\title{
Simulation of Water Equivalency of Polymer Gel Dosimeters with GAMOS
}

\author{
Türkan Özbay' ${ }^{1,2}$, Ayşegül Yurt'2, ${ }^{\circledR}$, İsmail Özsoykal ${ }^{2}$ \\ ${ }^{1}$ Izmir University of Economics, Vocational School of Health Services, Izmir,Turkey \\ ${ }^{2}$ Dokuz Eylul University, Department of Medical Physics, İzmir, Turkey \\ ${ }^{3}$ Dokuz Eylul University, Vocational School of Health Services, Izmir, Turkey \\ Address for Correspondence: Türkan Özbay, E-mail: turkan.ozbay@ieu.edu.tr \\ Received: 12.06.2019: Accepted: 10.12.2019: Available Online Date: 27.01.2020 \\ CCopyright 2019 by Dokuz Eylül University, Institute of Health Sciences - Available online at www.jbachs.org \\ Cite this article as: Özbay T, Yurt A, Özsoykal I. Simulation of Water Equivalency of Polymer Gel Dosimeters with GAMOS. J Basic Clin Health Sci 2020; 1:51-58.
}

\begin{abstract}
Purpose: Polymer gel materials are used as dosimeters to provide three dimensional radiation dose distribution. An ideal gel dosimeter should offer radiological properties equivalent to water. This study aims to determine and compare the water equivalencies of various new polymer gel mixtures using Geant4-based Architecture for Medicine-Oriented Simulations (GAMOS) software program.

Methods: To do this, percentage depth dose curves of the simulated polymer gel mixtures were compared with water curves. Different combinations of materials from 2 main classes were used in the mixtures: (1) Sodium Carboxymethyl Cellulose (SODIUM CMC), Polyvinyl Alcohol (PVA) and Polyethylene Glycol (PEG) as gel matrix, (2) 2-Hydroxyethyl Methacrylate (HEMA), 1-Vinyl-2-Pyrrolidinone (VP) and Diethylene Glycol Dimethacrylate (DEGDMA) as monomer. Each mixture also contained ultra-pure water and an antioxidant material called Tetrakis Hydroxymethyl Phosphonium Chloride (THPC).

Results: Percentage depth doses of gel mixtures and water was calculated for $6,18 \mathrm{MV}$ and 50, 70, 100, $150 \mathrm{kVp}$ X rays. The mixture sample showing radiological behavior nearest to water over all energies was observed to be $31 \mathrm{a}$ (Water, PEG, HEMA, THPC), while the largest difference is observed in 11a (Water, SODIUM CMC, HEMA, THPC).

Conclusion: As a result, simulated gel formulations were found to be radiologically water equivalent.

Keywords: Polymer gel, Dosimeter, Monte Carlo, GAMOS, Simulation
\end{abstract}

\section{INTRODUCTION}

There are a number of radiation measurement tools used in clinical practice based on radiation therapy and imaging applications, each with relative advantages and disadvantages. One tool, gel dosimeters, are produced from radiation-sensitive chemicals, which after irradiation, are polymerized as a function of the absorbed dose. For this reason, compared to other equipment, such as ion chambers and film dosimeters, they are able to deliver more precise three dimensional (3D) dose distributions and display better dosimeter performance. Gel dosimeters can also be used as phantoms since they are mostly composed of water equivalent materials. Two commonly used gel materials are Fricke and polymer gels. Polymer gel dosimeters exhibit more reliable results compared to Fricke type gel dosimeters, since they are unaffected by ferric ion diffusion, which may cause relatively misleading dosimetry (1).

Polymer gel dosimeter consists of monomers dissolved in the gel matrix and polymerized by free radicals resulting from the radiolysis of water molecule. The amount of polymerization occurring in the polymer gel is related to the absorbed dose. The gel matrix preserves the spatial integrity of the polymers, and dose distribution can be determined by imaging modality such as magnetic resonance imaging (MRI) (2-4), computed tomography (CT) $(5,6)$, ultrasound $(7,8)$, optical computed tomography (9-11) and vibration spectroscopy (12-14). Due to its nature, polymer gel dosimeter provides high spatial resolution, precision and 3 dimensional accuracy, making it a valuable tool for analyzing 3D dose distribution and confirming complex treatment plans. The importance of gel dosimetry in modern radiation therapy has been previously emphasized (1-14).

Many authors have expressed concern about the excess toxicity of acrylamide found in commonly used polyacrylamide gel (PAG) dosimeters. Acrylamide is a serious neurotoxin and it is thought to be a human carcinogen and teratogen, and is easily absorbed through the skin (15). For this reason, considering the radiological 
water equivalency of the polymer gel dosimeters, it is crucial to develop the research and use of less toxic monomers with a similar chemical structure to acrylamide. This simulation based study aims to focus on alternative gel compositions, based on different monomers, which is both safe and reliable.

The rapid development of computers allows modeling of the interaction of ionizing radiation with matter and dose information stored in matter to be determined with great accuracy within reasonable time (16). In order to simulate radiation transport, various algorithms and various codes have been developed. Monte Carlo method is a methodology that is used to solve mathematical and physical problems using a simulation technique. Another important application of Monte Carlo-based simulation programs used for many purposes, such as detector response, image reconstruction and evaluation of image quality, is to assess tissue equivalence of materials as dosimetry or phantom material $(17,18)$.

There are many Monte Carlo codes that are successfully used in radiotherapy simulations. The most popular ones are: BEAMnrc (19), MCNP (20), PENELOPE (21) and GEANT4 (22). These codes use certain programming languages such as $\mathrm{C}++$, which makes it difficult for researchers who are not familiar with such programming languages. On the other hand, there are some software programs acting as an interface between the user and the main programs mentioned above. These secondary software programs use the primary code of software but not requires any knowledge of programming language from the user. GAMOS software is one of them. It is built based on GEANT4 and widely used for simulation studies in medical physics $(23,24)$.

The purpose of this study is to construct necessary irradiation setup geometries in GAMOS and compare the percentage depth dose curves (PDD) of different polymer gel materials and water for diagnostic and radiotherapy X-ray energies. After these comparisons, gel mixtures with the radiological properties closest to water will be identified for the experimental part of the study, and will be produced for testing.

\section{METHODS}

\section{Polymer gel mixtures}

There are two categories of gel mixtures in this simulation study. In the first category are the combinations of two main components; gel matrices and monomers which are mixed in two different amounts ( $\mathrm{a}$ and $\mathrm{b}$ ) with water and an antioxidant material called Tetrakis (Hydroxymethyl) Phosphonium Chloride (THPC) (Table 1). In these mixtures, CMC, PVA and PEG were used as gel matrices, while HEMA, VP and DEGDMA were used as monomers. The percentages of gel mixtures used in this study were determined based on the most commonly used values in the literature $(1,25$, 26). A second category was created to observe the influence of the crosslinking agent on the water equivalency of the mixture. In this category, VP and DEGDMA were also used as crosslinking agents, replacing half the amount of monomer. The polymer gel mixtures were combined in two different amounts, $\mathrm{a}$ and $\mathrm{b}$ (Table 2).

\begin{tabular}{llcc}
\hline \multicolumn{3}{l}{ Table 1. Composition of polymer gel mixtures without crosslinking agents. } \\
\hline Component Type & $\begin{array}{l}\text { Component } \\
\text { Name }\end{array}$ & $\begin{array}{c}\text { Amount [\%] } \\
\text { [a] }\end{array}$ & $\begin{array}{c}\text { Amount [\%] } \\
\text { [b] }\end{array}$ \\
\hline Liquid Medium & $\begin{array}{l}\text { Water } \\
\text { 1. SODIUM CMC }\end{array}$ & 88,85 & 85,85 \\
Gel Matrix & $\begin{array}{l}\text { 2. PVA } \\
\text { 3. PEG }\end{array}$ & 5 & 5 \\
Monomer & $\begin{array}{l}\text { 1. HEMA } \\
\text { 2. VPe }\end{array}$ & \multicolumn{1}{c}{6} & \\
Antioxidant & $\begin{array}{l}\text { 3. DEGDMA } \\
\text { THPC }\end{array}$ & 6 & 9 \\
\hline
\end{tabular}

aSodium Carboxymethyl Cellulose

bPolyvinyl Alcohol

cPolyethylene Glycol

${ }^{d}$ Hydroxyethyl Metacrylate

eVinyl Pyrrolidinone

fDiethylene Glycol Dimetacrylate

sTetrakis Hydroxymethyl Phosphonium Chloride

\begin{tabular}{|c|c|c|c|}
\hline Component Type & $\begin{array}{l}\text { Component } \\
\text { Name }\end{array}$ & $\begin{array}{l}\text { Amount [\%] } \\
{[\mathrm{a}]}\end{array}$ & $\begin{array}{c}\text { Amount [\%] } \\
\text { [b] }\end{array}$ \\
\hline \multirow[t]{2}{*}{ Liquid Medium } & Water & 88,85 & 85,85 \\
\hline & 1. SODIUM CMC & & \\
\hline \multirow[t]{3}{*}{ Gel Matrix } & 2. $\mathrm{PVA}^{\mathrm{b}}$ & 5 & 5 \\
\hline & 3. $\mathrm{PEG}^{\mathrm{c}}$ & & \\
\hline & 1. $\mathrm{HEMA}^{\mathrm{d}}$ & & \\
\hline \multirow[t]{2}{*}{ Monomer } & 2. VPe & 3 & 4.5 \\
\hline & 3. DEGDMA ${ }^{f}$ & & \\
\hline \multirow{2}{*}{ Crosslinking Agent } & 1. DEGDMA & 3 & 45 \\
\hline & 2. VP & 3 & 4.5 \\
\hline Antioxidant & THPCg & 0.15 & 0.15 \\
\hline \multicolumn{4}{|c|}{ a Sodium Carboxymethyl Cellulose } \\
\hline \multicolumn{4}{|c|}{${ }_{\mathrm{b}}$ Polyvinyl Alcohol } \\
\hline \multicolumn{4}{|l|}{ c Polyethylene Glycol } \\
\hline \multicolumn{4}{|c|}{${ }^{d}$ Hydroxyethyl Metacrylate } \\
\hline \multicolumn{4}{|c|}{ e Vinyl Pyrrolidinone } \\
\hline \multicolumn{4}{|c|}{${ }^{\mathrm{f}}$ Diethylene Glycol Dimetacrylate } \\
\hline g Tetrakis Hydroxymeth & yl Phosphonium Chlc & & \\
\hline
\end{tabular}

\section{Monte Carlo simulation}

GAMOS v.5.1.0 software program was used for the simulations in this study. The hardware equipment used in this study included two work stations with Intel Xeon ${ }^{\circledR}$ CPU E5630 4x2x(HT) 2.53 $\mathrm{GHz}$ and 64 bit processors with $24 \mathrm{GiB}$ random access memory. Geometry was designed such that there was $100 \mathrm{~cm}$ distance between the source and the target. Initial target material was a cube of water with dimensions $100 \times 100 \times 100 \mathrm{~cm}^{3}$. Afterwards, gel mixture volumes of $10 \times 10 \times 10 \mathrm{~cm}^{3}$ dimensions were placed in the center of the target surface corresponding to the source. A $10 \mathrm{~cm}$ thick tungsten collimator block was placed between the source and the target to obtain a radiation field of $10 \times 10 \mathrm{~cm}^{2}$ at the target surface (Figure 1). Source, block and target were placed coaxially in the geometry. Each mixture volume was divided into 100 consecutive voxels in the direction of primary beam in order to give 100 consecutive (i.e. per $\mathrm{mm}$ ) dose values along the depth of $10 \mathrm{~cm}$. Every mixture was irradiated at $50 \mathrm{kVp}, 70 \mathrm{kVp}, 100$ $\mathrm{kVp}, 150 \mathrm{kVp}, 6 \mathrm{MV}$ and $18 \mathrm{MV}$ photon energies and PDD were recorded in text files. 


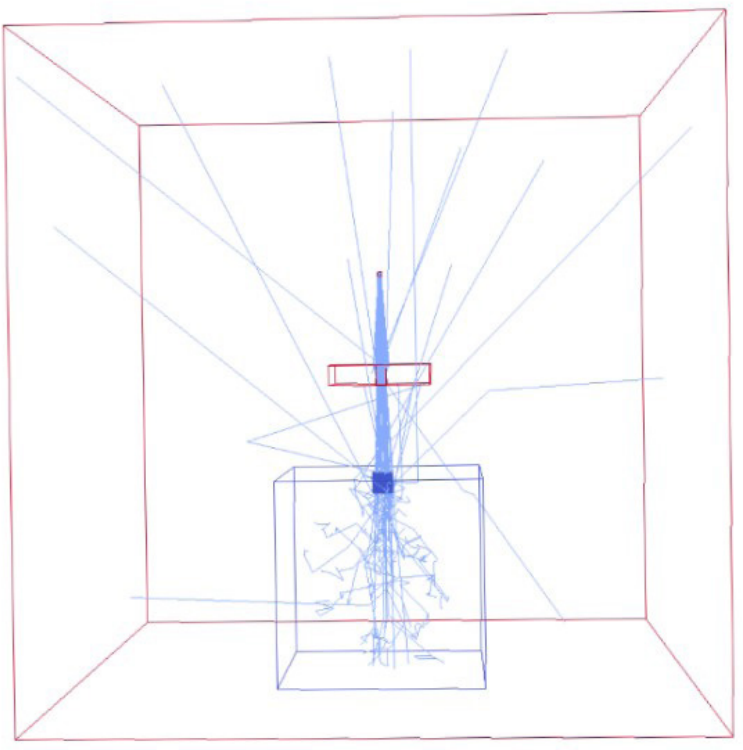

Figure 1. Source, block and target geometry in GAMOS with $10 \times 10 \mathrm{~cm}^{2}$ irradiation field and source to target distance of $100 \mathrm{~cm}$.

In the geometry file, for means of simplification of the simulation, source model was represented in the form of energy spectrums generated with $1 \times 10^{8}$ histories. The energy spectrums for the photon beams at $\mathrm{kVp}$ range were obtained by using SPEKTR 3.0 program (27) while $6 \mathrm{MV}$ and $18 \mathrm{MV}$ spectrums were obtained from the linear accelerator (Primus, Siemens) system database. Any particle in the simulation has been tracked until losing its energy down to $990 \mathrm{eV}$, which was a default value set by GAMOS.

\section{Validation of the GAMOS Code}

Prior to obtaining the results, a test was carried out on the constructed model to validate its operation. This test included the PDD values obtained from the measurement made for $6 \mathrm{MV}$ photon beams. The measurements was made in a water phantom using a calibrated ionization chamber. Then a similar setup was modelled in GAMOS and PDD values were obtained. In both classes of PDDs, depth of the maximum dose $\left(\mathrm{d}_{\max }\right)$ and ratio of the $20 \mathrm{~cm}$ depth dose to the $10 \mathrm{~cm}$ depth dose $\left(\mathrm{TPR}_{20,10}\right)$ values were recorded and compared.

\section{Comparison and analysis of data}

PDD data was obtained for all polymer gel mixtures and water at all energies. Each single PDD dataset consisted of 100 consecutive relative dose values, normalized to the maximum dose. Water equivalency of the mixtures was examined over the comparison and analysis of these datasets, as shown in equation 1;

$\mathrm{D}(\mathrm{z})=\frac{M(z)-W(z)}{W(z)} * 100$

where $D(z)$ represents the percentage difference between the relative dose values of polymer gel mixture $(M)$ and water $(\mathrm{W})$ at depth $z$ ranging from 1 to $100 \mathrm{~mm}$. Third quartiles (Q3) of these datasets were determined for each polymer gel mixture in order to compare the behaviour of different mixtures at a single energy, and also the behaviour of a single mixture at different energies.

OriginPro 2017 (OriginLab, Northampton, MA, USA) was used to plot $\mathrm{D}(\mathrm{z})$ against depth $(\mathrm{z})$ for radiologically the least and the most water equivalent polymer gel mixtures at different energies.

\section{RESULTS}

Validation test of the constructed model in GAMOS yielded reasonable results as shown in Table 3. Table 4 shows the Q3 values of the difference between water and polymer gel mixtures without any crosslinking agent. The mixture sample showing radiological behavior nearest to water over all energies was observed to be 31 a coded sample, while the largest difference is observed in $11 \mathrm{a}$ coded sample. These samples' PDDs and difference relative to water are plotted against depth in Figure 2.

\begin{tabular}{|c|c|c|c|}
\hline & Measurement & Simulation & $\begin{array}{c}\text { Difference } \\
\text { [\%] }\end{array}$ \\
\hline $\mathrm{D}_{\max }{ }^{\mathrm{a}}(\mathrm{cm})$ & 1.6 & 1.6 & - \\
\hline $\mathrm{TPR}_{20,10^{\mathrm{b}}}$ & 0.67 & 0.657 & 1.9 \\
\hline
\end{tabular}

adepth of maximum dose

btissue to phantom ratio

In the second category of mixtures with crosslinking agents, sample 311 a exhibited the radiological behaviour nearest to water, while the largest difference has been observed in 111a (Table 5). On the other hand, Figure 3 shows the results of radiologically the least (111a) and the most (311a) water equivalent mixtures, which include crosslinking agent.

Table 4. Q3 values of the difference between water and polymer gel mixtures without crosslinking agent.

\begin{tabular}{|c|c|c|c|c|c|c|c|c|c|c|c|c|c|c|c|c|c|c|c|}
\hline \multirow{2}{*}{\multicolumn{2}{|c|}{ Gel Mixtures }} & \multicolumn{6}{|c|}{ Group 1} & \multicolumn{6}{|c|}{ Group 2} & \multicolumn{6}{|c|}{ Group 3} \\
\hline & & $11 a$ & $11 b$ & $12 a$ & $12 b$ & $13 a$ & $13 b$ & $21 a$ & $21 b$ & $22 a$ & $22 b$ & $23 a$ & $23 b$ & $31 a$ & $31 b$ & $32 a$ & $32 b$ & $33 a$ & $33 b$ \\
\hline \multirow{5}{*}{ Energy } & $50 \mathrm{kVp}$ & 4,8 & 4,1 & 3,7 & 2,5 & 4,6 & 4 & 3,2 & 3,7 & 4,1 & 5,4 & 3,1 & 3,9 & 1 & 1,7 & 2 & 3,1 & 1,1 & 1,7 \\
\hline & 70 kVp & 3,8 & 3,5 & 3,2 & 2,5 & 3,8 & 3,3 & 1,7 & 2,1 & 2,3 & 3,2 & 1,8 & 2,2 & 0,3 & 0,7 & 1 & 1,7 & 0,4 & 0,7 \\
\hline & $100 \mathrm{kVp}$ & 3 & 2,7 & 2,6 & 2,1 & 3,2 & 2,9 & 1 & 1,3 & 1,7 & 2,3 & 1,2 & 1,5 & 0,2 & 0,4 & 0,6 & 1 & 0,2 & 0,4 \\
\hline & $150 \mathrm{kVp}$ & 2,5 & 2,5 & 2,1 & 1,9 & 2,6 & 2,3 & 0,9 & 1 & 1,4 & 1,6 & 1 & 1,1 & 0,3 & 0,4 & 0,3 & 0,7 & 0,2 & 0,3 \\
\hline & $6 \mathrm{MV}$ & 0,8 & 0,8 & 0,7 & 0,7 & 0,8 & 0,8 & 0,2 & 0,2 & 0,4 & 0,2 & 0,2 & 0,2 & 0,3 & 0,2 & 0,2 & 0,2 & 0,2 & 0,4 \\
\hline
\end{tabular}




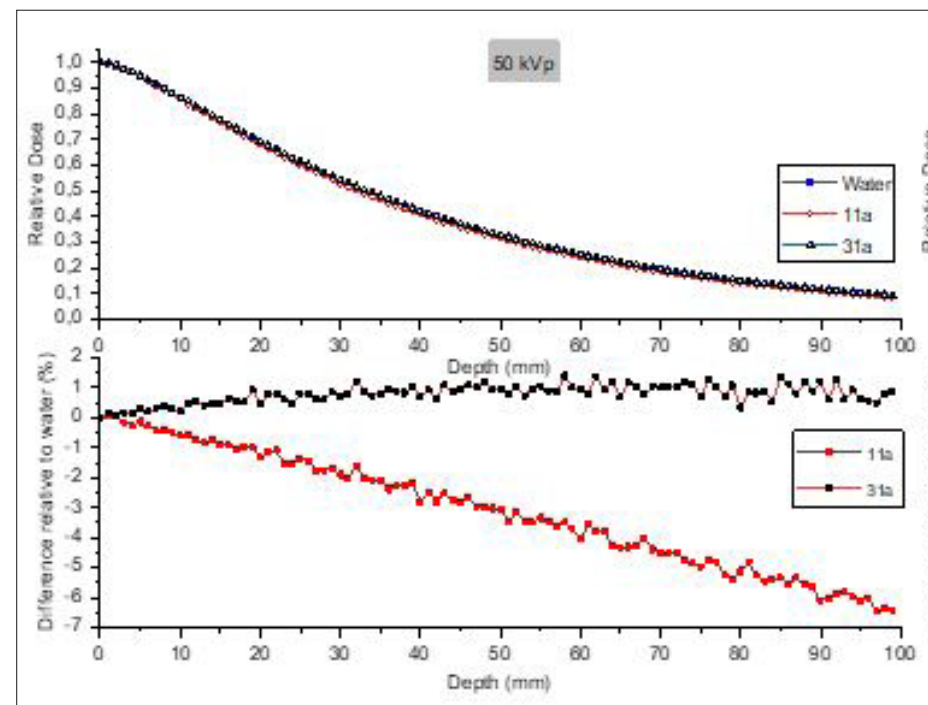

a)

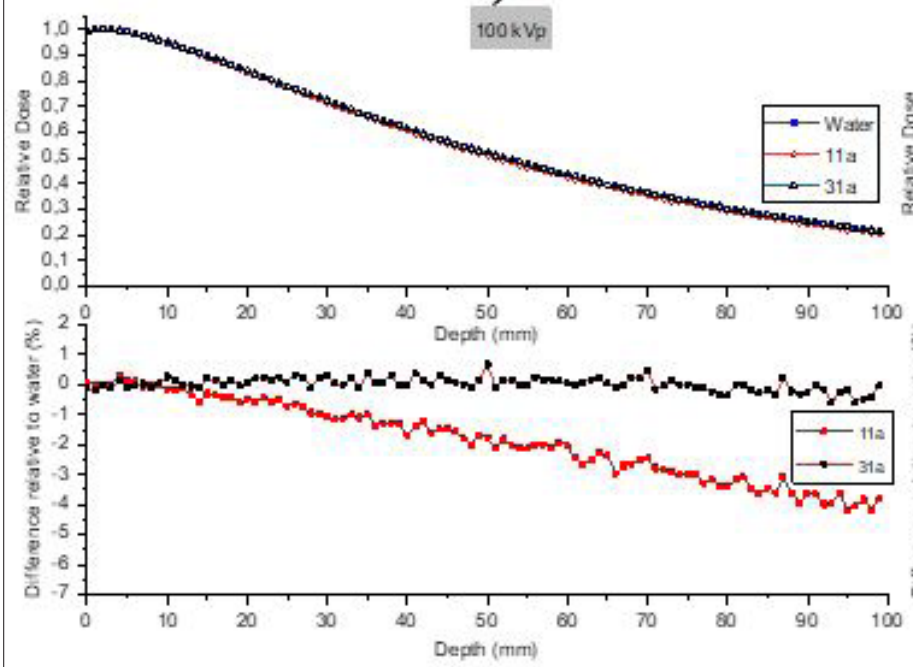

c)
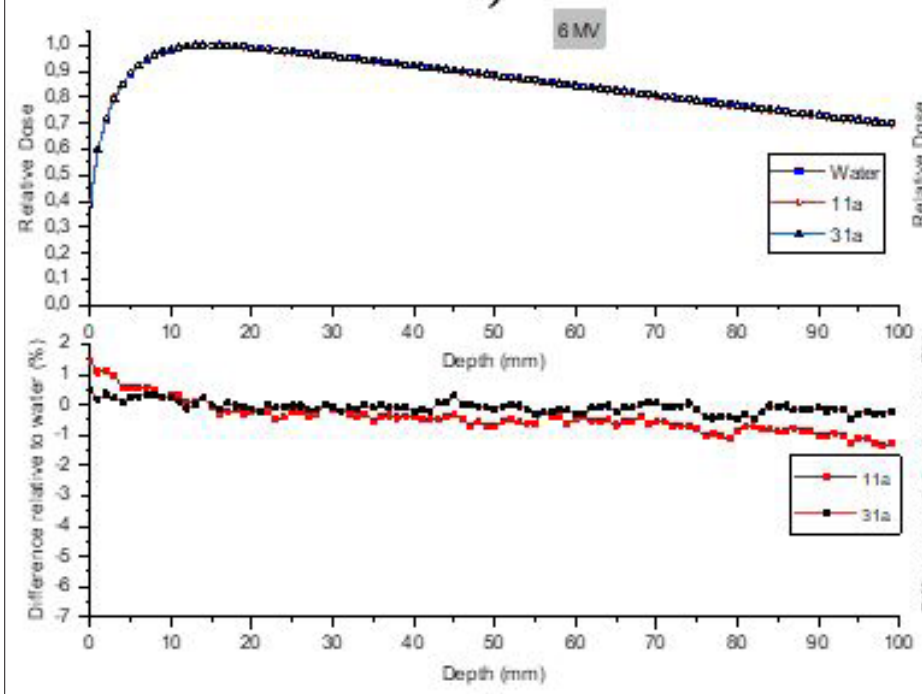

e)

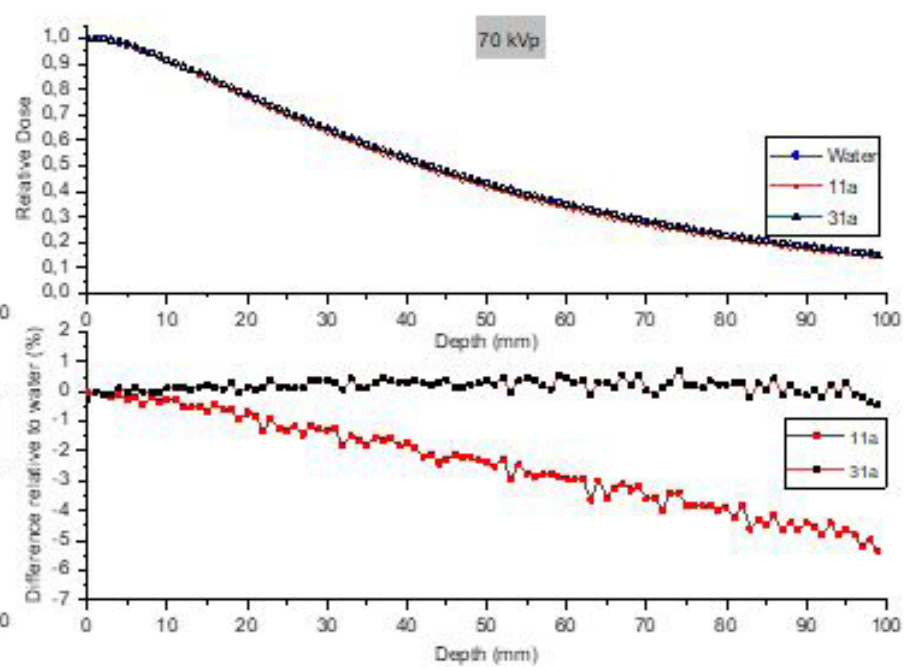

b)
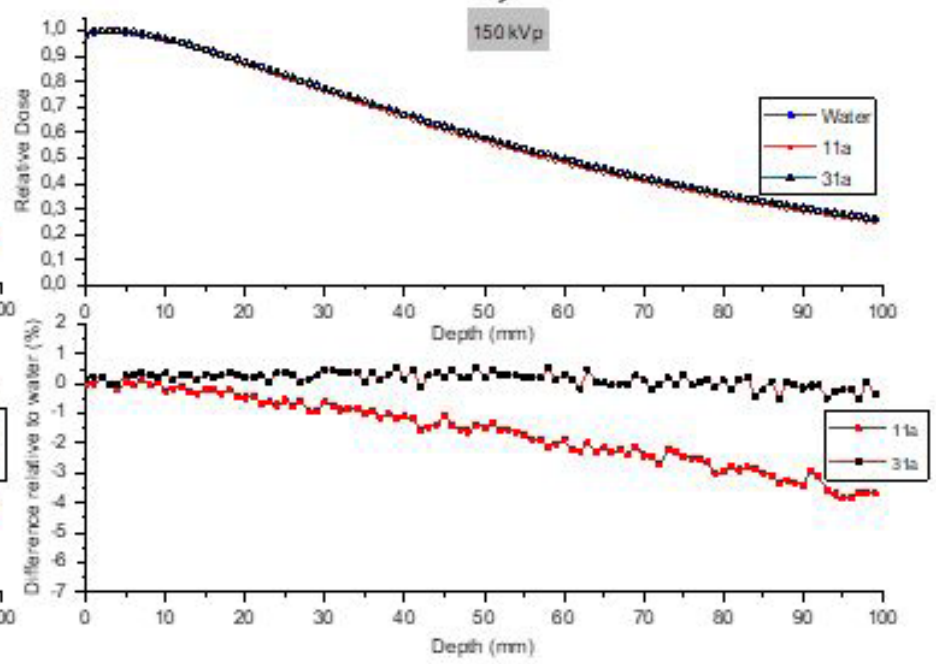

d)
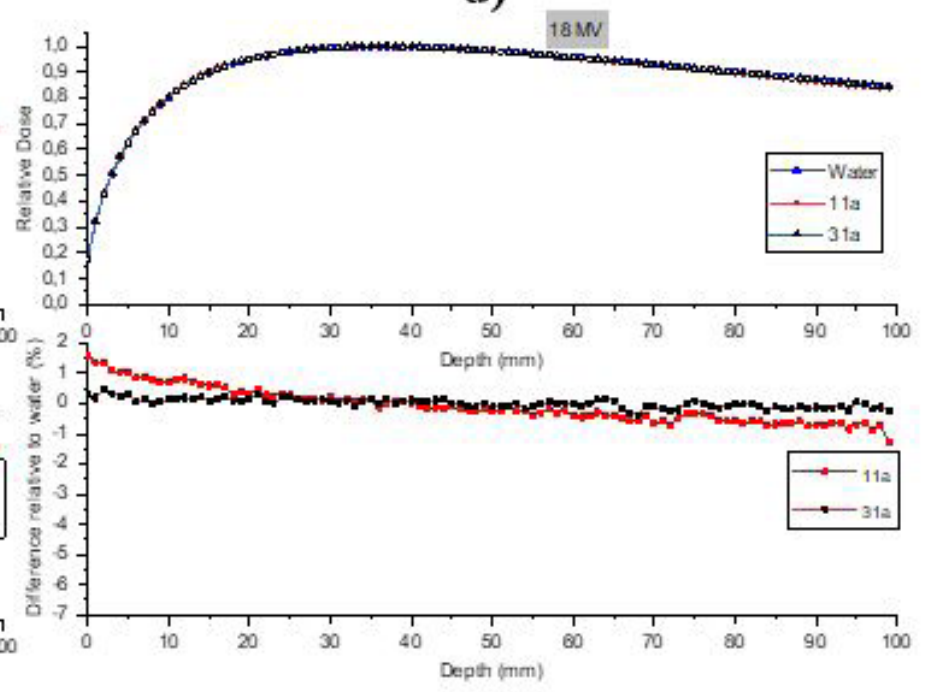

f)

Figure 2. PDD and relative difference of mixtures without crosslinking agent (11a and $31 \mathrm{a})$ according to water at (a) $50 \mathrm{kVp}$, (b) $70 \mathrm{kVp}$, (c) $100 \mathrm{kVp}$, (d) $150 \mathrm{kVp}$, (e) $6 \mathrm{MV}$ ve (f) $18 \mathrm{MV}$. 


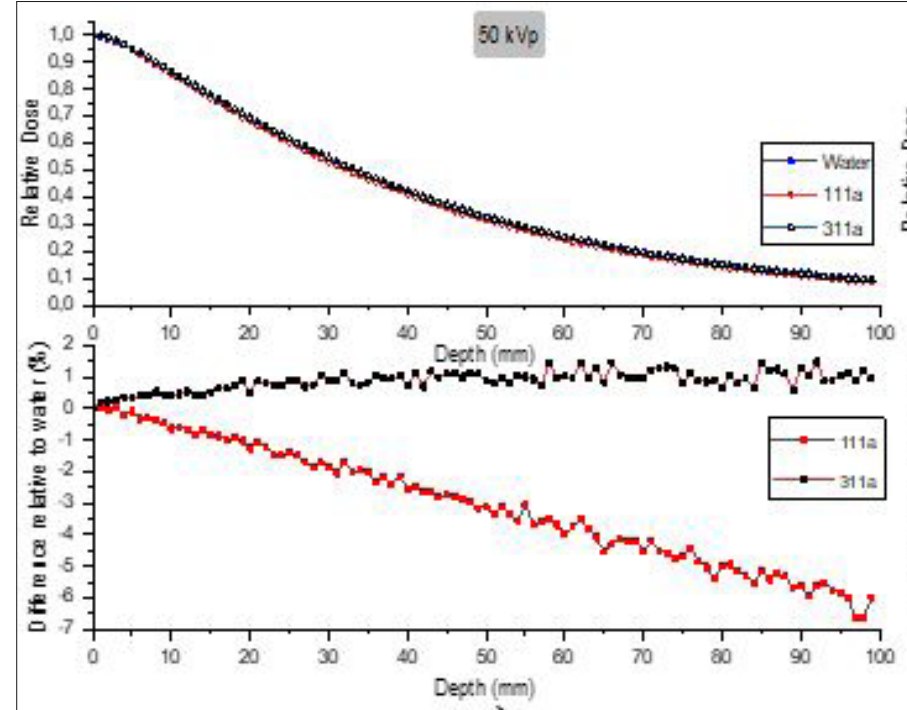

a)
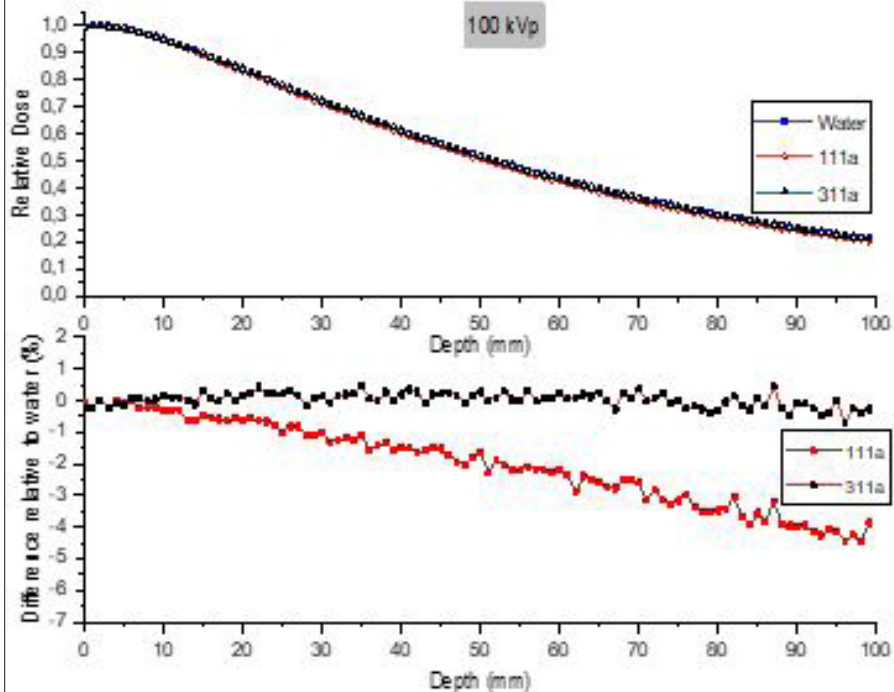

c)

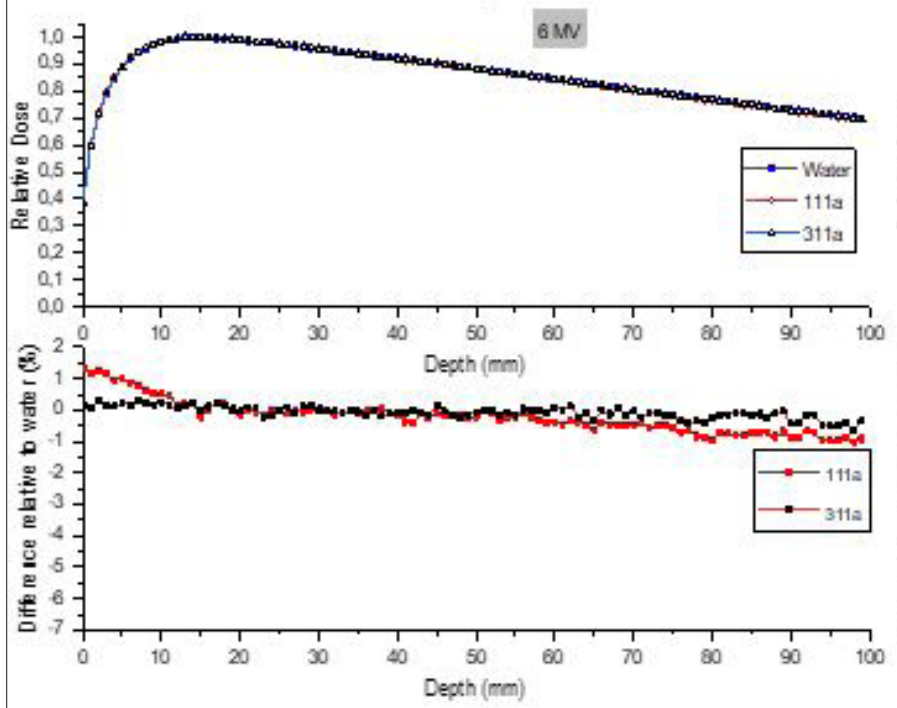

e)

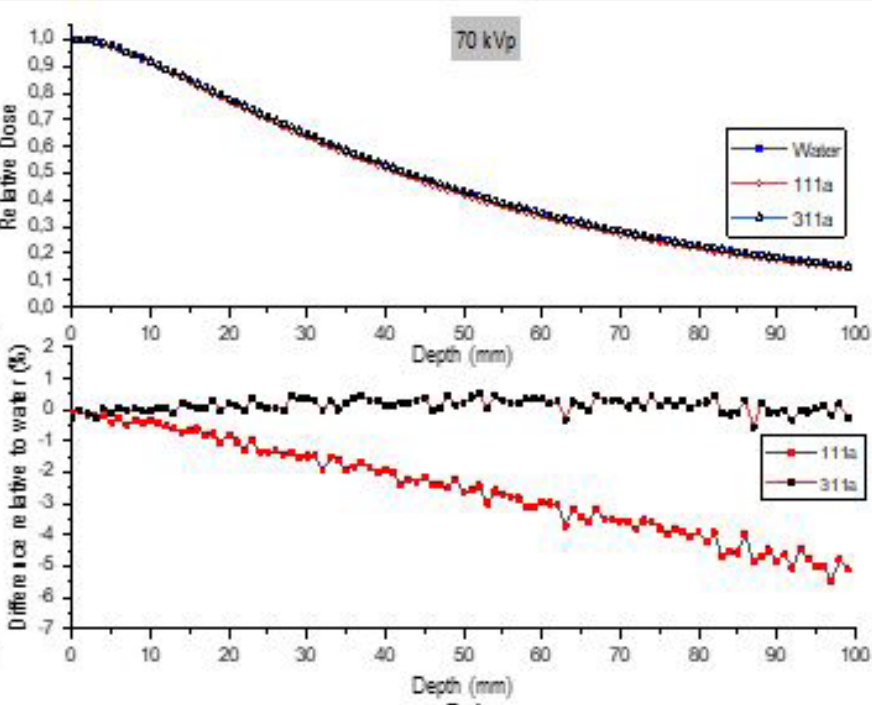

b)

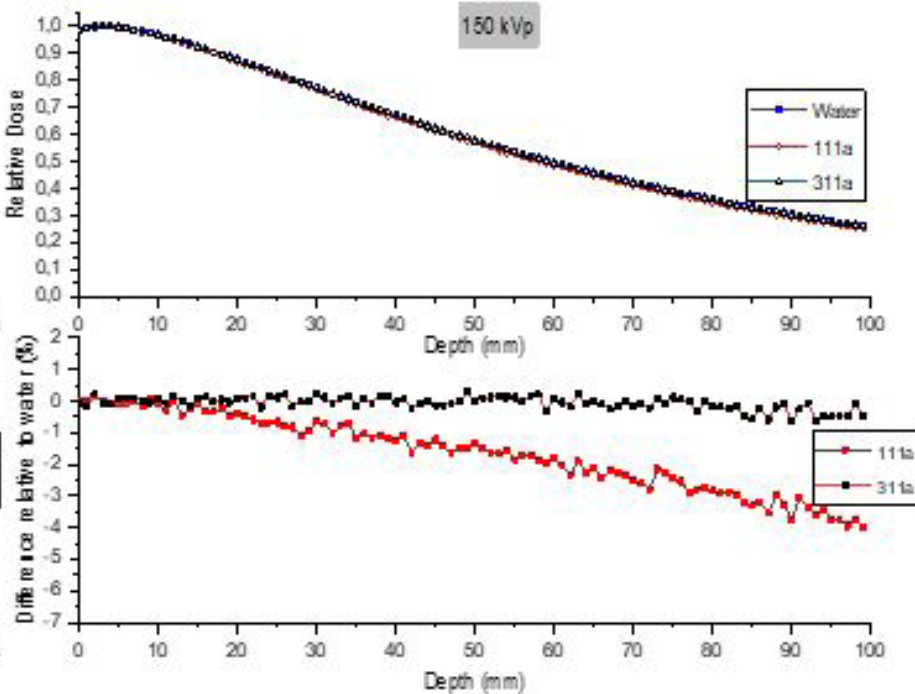

d)

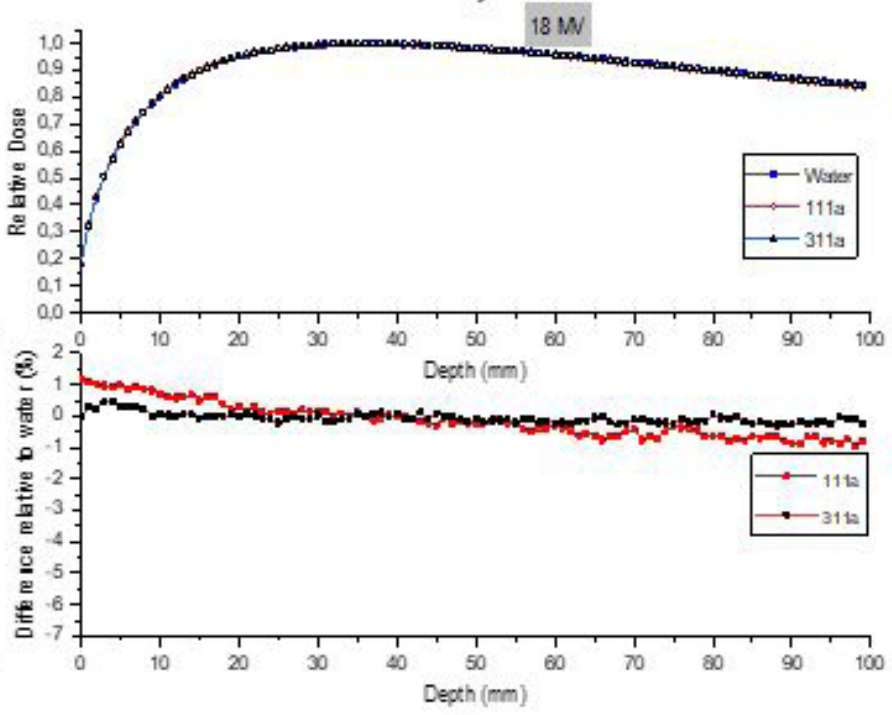

f)

Figure 3. PDD and relative difference of mixtures with crosslinking agent (111a and 311a) according to water at (a) $50 \mathrm{kVp}$, (b) $70 \mathrm{kVp}$, (c) $100 \mathrm{kVp}$, (d) $150 \mathrm{kVp}$, (e) $6 \mathrm{MV}$ ve (f) $18 \mathrm{MV}$. 
Table 5. Q3 values of the difference between water and polymer gel mixtures with crosslinking agent

\begin{tabular}{|c|c|c|c|c|c|c|c|c|c|c|c|c|c|c|}
\hline \multirow{8}{*}{ a] } & \multirow{2}{*}{\multicolumn{2}{|c|}{ Gel Mixtures }} & \multicolumn{12}{|c|}{ Group 1 [ Gel matrix: SODIUM CMCa] } \\
\hline & & & $111 \mathrm{a}$ & $111 b$ & $112 a$ & $112 b$ & $121 \mathrm{a}$ & $121 \mathrm{~b}$ & $122 a$ & $122 b$ & $131 \mathrm{a}$ & $131 b$ & $132 a$ & $132 b$ \\
\hline & \multirow{6}{*}{ Energy } & $50 \mathrm{kVp}$ & 4,6 & 3,9 & 4,1 & 3,3 & 4,1 & 3,3 & 3,7 & 2,5 & 4,6 & 4 & 4,1 & 3,3 \\
\hline & & 70 kVp & 3,8 & 3,5 & 3,5 & 2,9 & 3,4 & 2,9 & 3,2 & 2,5 & 3,8 & 3,3 & 3,4 & 2,9 \\
\hline & & $100 \mathrm{kVp}$ & 3,1 & 2,8 & 2,7 & 2,5 & 2,8 & 2,5 & 2,6 & 2,1 & 3,2 & 2,9 & 2,8 & 2,5 \\
\hline & & $150 \mathrm{kVp}$ & 2,6 & 2,3 & 2,3 & 2 & 2,4 & 2 & 2,1 & 1,9 & 2,6 & 2,3 & 2,4 & 2 \\
\hline & & $6 \mathrm{MV}$ & 0,7 & 0,8 & 0,7 & 0,7 & 0,8 & 0,6 & 0,7 & 0,7 & 0,8 & 0,8 & 0,8 & 0,6 \\
\hline & & $18 \mathrm{MV}$ & 0,7 & 0,2 & 0,2 & 0,1 & 0,2 & 0,1 & 0,6 & 0,6 & 0,6 & 0,6 & 0,2 & 0,1 \\
\hline \multirow{8}{*}{ b] } & \multirow{2}{*}{\multicolumn{2}{|c|}{ Gel Mixtures }} & \multicolumn{12}{|c|}{ Group 2 [ Gel matrix: PVAb] } \\
\hline & & & $211 a$ & $211 b$ & $212 a$ & $212 b$ & $221 a$ & $221 b$ & $222 a$ & $222 b$ & $231 a$ & $231 \mathrm{~b}$ & $232 a$ & $232 b$ \\
\hline & \multirow{6}{*}{ Energy } & $50 \mathrm{kVp}$ & 0,5 & 2,0 & 2,3 & 1,8 & 2,9 & 1,6 & 4,1 & 5,4 & 3,1 & 3,9 & 2,9 & 1,6 \\
\hline & & $70 \mathrm{kVp}$ & 0,6 & 2,1 & 2,3 & 0,6 & 1,5 & 0,7 & 2,3 & 3,2 & 1,8 & 2,2 & 1,5 & 0,7 \\
\hline & & $100 \mathrm{kVp}$ & 0,7 & 2 & 2,1 & 0,4 & 1 & 0,3 & 1,7 & 2,3 & 1,2 & 1,5 & 1 & 0,3 \\
\hline & & $150 \mathrm{kVp}$ & 0,6 & 2 & 2 & 0,3 & 0,8 & 0,4 & 1,4 & 1,6 & 1 & 1,1 & 0,8 & 0,4 \\
\hline & & $6 \mathrm{MV}$ & 0,5 & 1,1 & 0,8 & 0,3 & 0,2 & 0,5 & 0,4 & 0,2 & 0,2 & 0,2 & 0,2 & 0,5 \\
\hline & & $18 \mathrm{MV}$ & 0,7 & 0,3 & 0,2 & 0,1 & 0,1 & 0,1 & 0,2 & 0,2 & 0,2 & 0,2 & 0,1 & 0,1 \\
\hline \multirow{8}{*}{ c] } & \multirow{2}{*}{\multicolumn{2}{|c|}{ Gel Mixtures }} & \multicolumn{12}{|c|}{ Group 3 [ Gel matrix: PEGc] } \\
\hline & & & $311 a$ & $311 b$ & $312 a$ & $312 b$ & $321 a$ & $321 b$ & $322 a$ & $322 b$ & $331 a$ & $331 b$ & $332 a$ & $332 b$ \\
\hline & \multirow{6}{*}{ Energy } & $50 \mathrm{kVp}$ & 1,1 & 2,0 & 2,6 & 1,1 & 1,5 & 1,1 & 2 & 3,1 & 1,1 & 1,7 & 1,5 & 1,1 \\
\hline & & 70 kVp & 0,3 & 2,1 & 2,7 & 0,5 & 0,6 & 0,4 & 1 & 1,7 & 0,4 & 0,7 & 0,6 & 0,4 \\
\hline & & $100 \mathrm{kVp}$ & 0,3 & 2 & 2,3 & 0,4 & 0,4 & 0,4 & 0,6 & 1 & 0,2 & 0,4 & 0,4 & 0,4 \\
\hline & & $150 \mathrm{kVp}$ & 0,2 & 2 & 2,3 & 0,4 & 0,4 & 0,4 & 0,3 & 0,7 & 0,2 & 0,3 & 0,4 & 0,4 \\
\hline & & $6 \mathrm{MV}$ & 0,2 & 0,3 & 1 & 0,4 & 0,2 & 0,5 & 0,2 & 0,2 & 0,2 & 0,4 & 0,2 & 0,5 \\
\hline & & $18 \mathrm{MV}$ & 0,2 & 0,1 & 0,2 & 0,2 & 0,3 & 0,2 & 0,3 & 0,2 & 0,2 & 0,2 & 0,3 & 0,2 \\
\hline
\end{tabular}

\section{DISCUSSION}

An ideal polymer gel dosimeter must provide accurate dosimetric results at both low and high energy radiation. This is possible with a composition that displays water equivalent characteristics when it is exposed to low and high energy particles.

Mixtures with the initial digit of 1 are those that contain SODIUM $\mathrm{CMC}$, the chemical with the highest mass density of all the mixture components, $1.6 \mathrm{~g} / \mathrm{cm}^{3}$. In addition, SODIUM is the element with the highest atomic number of all the mixtures. This increased the probability of photoelectric absorption in mixtures $11 \mathrm{a}$ and $111 \mathrm{a}$ at energies within the $\mathrm{kVp}$ range, resulting in a lower penetration ability of the beam. For this reason, when compared to water, lower doses with a percentage difference up to $7 \%$ were observed with increasing depth. However, this is not the case for higher energies, where the interactions are dominated mostly by Compton scattering.

On the other hand, polymer gel mixtures with PEG as gel matrix, having the initial digit of 3 , displayed significantly more water equivalent characteristics for all energies and depths, due to PEG's lower mass density, $1.13 \mathrm{~g} / \mathrm{cm}^{3}$.
When the difference with respect to water is considered for the mixtures $31 \mathrm{a}$ and $311 \mathrm{a}$, it is observed that the maximum values of percentage difference are $1.4 \%$ and $1.5 \%$, respectively, occurring at $50 \mathrm{kVp}$ for both mixtures. This can be interpreted as the crosslinking agents used in this study do not have a significant role on the water equivalency of the mixture. However, the effect of this materials will be examined further in the experimental part of this study, since they may have an influence on the polymerization process and therefore dose response of the gel.

Similar studies reviewed in the literature were carried out by using EGSnrc and BEAMnrc codes for simulation. In contrast, the current study is the only one to utilize GAMOS code.

Venning et al. (2005b) studied on MAGIC, MAGAS and MAGAT dosimeters, and investigated their water equivalency over PDD curves. The largest differences with respect to water at $6 \mathrm{MV}$ have been reported as $3.5 \%, 3.5 \%$ and $3 \%$ for MAGIC, MAGAS and MAGAT, respectively (28).

In studies carried out by Gorjiara et al., PRESAGE gel dosimeter was examined in the same respect. The results reported between an energy range of $50 \mathrm{kVp}$ and $6 \mathrm{MV}$ showed that the gels with 
lower halogen content were superior to original PRESAGE with the maximum difference of $4 \%$ versus $12 \%$. In this study, maximum differences with respect to water were at $50 \mathrm{kVp}$, and observed to decrease with the increasing beam energy, which is parallel to the findings in our study $(29,30)$. Another simulation study carried out by Gorjiara et al. showed that genipin gel exhibits a better performance, with a maximum difference of $0.8 \%$ at $6 \mathrm{MV}(31)$.

Our results indicate that $31 a-b$ and $33 a-b$ gel formulations show the best water equivalent dose response for the 70-150 kVp, 6 and 18 MV x-ray beams. In addition, group 3 compositions including crosslinking agents were found to have a better water equivalency, except for 311b, 312a and 322b.

This is a simulation study in which the actual measurement setup has been modeled by reasonable assumptions. However, GAMOS, while modeling radiation interactions with matter very accurately, cannot account for any chemical changes that occur in the matter due to radiation exposure and may yield different results. This study has compared various chemical composite materials for their physical properties. It should and will be followed by another study including actual irradiation and dosimetric evaluation procedures to overcome this limitation.

\section{CONCLUSION}

This study focused on the polymer gel mixtures which can be used as water equivalent dosimeters in radiology and radiotherapy departments. For this purpose, 54 different gel mixtures were composed and examined in a simulated medium.

Density and atomic number of the components play important roles in attaining this equivalency, as indicated by this study. Some of the results for the simulated gel mixtures yielded differences of

\section{REFERENCES}

1. Baldock $C$, De Deene $Y$, Doran $S$, et al. Polymer gel dosimetry. Phys Med Biol 2010;55:R1-R63. [CrossRef]

2. McJury M, Oldham M, Cosgrove VP, et al. Radiation dosimetry using polymer gels: methods and applications. Br J Radiol 2000;73:919929. [CrossRef]

3. De Deene Y, De Wagter C, Van Duyse B, et al. Validation of MR-based polymer gel dosimetry as a preclinical three dimensional verification tool in conformal radiotherapy. Magn Reson Med 2000;43:116-125. [CrossRef]

4. Maryanski MJ, Schulz RJ, Ibbott GS, et al. Magnetic resonance imaging of radiation dose distributions using a polymer-gel dosimeter. Phys Med Biol 1994;39:1437-1455. [CrossRef]

5. Brindha S, Venning AJ, Hill B, Baldock C. Experimental study of attenuation properties of normoxic polymer gel dosimeters. Phys Med Biol 2004;49:N353-N361. [CrossRef]

6. Hill B, Venning A, Baldock $C$. The dose response of normoxic polymer gel dosimeters measured using X-ray CT. BrJ Radiol 2005;78:623-630. [CrossRef] up to $7 \%$ compared to water, while other results were significantly closer. In the next step of this study, samples displaying the closest radiological properties to water (maximum percentage difference $<2 \%$ ) will be manufactured in laboratory conditions and tested experimentally before being recommended for use in clinical practice.

\section{Acknowledgments}

This study was supported by Dokuz Eylul University Scientific Research Coordination Unit (project number: 2018.KB.SAG.081). Apart from this, the authors would like to convey their special thanks to KadirAKGÜNGÖR and Hakan EPIK for their contributions with the construction of an Octave algorithm for analysis the results. The authors would like to thank to Gizem şisMAN and Recep KANDEMIR for providing the energy spectrums used in simulations. The authors would like to acknowledge the support of Dokuz Eylül University Hospital for permission to use the parallel computing Beowolf cluster laboratory. The authors also thank Simon MUMFORD for proofreading the article.

Compliance with Ethical Standards: This study was conducted in accordance with ethical standards under the responsibility of Institutional Review Board that has approved the study (Ref no: 2017/24-30)

Peer-review: Externally peer-reviewed.

Author Contributions: Concept - TÖ, AY, IÖ; Design - TÖ, AY, IÖ; Supervision - TÖ, AY iÖ; Fundings - TÖ, AY, IÖ; Materials - TÖ, AY, IÖ; Data Collection and/or Processing - TÖ, AY, IÖ; Analysis and/or Interpretation - TÖ, AY, IÖ; Literature Search - TÖ, AY, IÖ; Writing Manuscript - TÖ, AY, IÖ; Critical Review - TÖ, AY, IÖ

Conflict of Interest: No conflict of interest was declared by the authors.

Financial Disclosure: This study was supported by Dokuz Eylül University Scientific Research Project [grant number 2018. KB.SAG.081]

Presented as a poster in Turkish Physical Society 34th International Physics Congress, September 5-9, 2018

7. Zahran RR, Kandeil AY, Higazy AA, Kassem ME. Ultrasonic and thermal properties of gamma irradiated low-density polyethylene. J Appl Poly Sci 1993;49:1291-1297. [CrossRef]

8. Zahran RR. Effects of gamma irradiation on the ultrasonic and structural properties of polyoxymethylene. Mater Lett 1998;37:83-89. [CrossRef]

9. Maryanski MJ, Zastavker YZ, Gore JC. Radiation dose distributions in three dimensions from tomographic optical density scanning of polymer gels: II. Optical properties of the BANG polymer gel. Phys Med Biol 1996;41:2705. [CrossRef]

10. Oldham M, Siewerdsen JH, Shetty A, Jaffray DA. High resolution geldosimetry by optical-CT and MR scanning. Med Phys 2001;28:14361445. [CrossRef]

11. Maryanski MJ, Ranade MK. Laser micro-beam scanning of dosimetry gels. Proc SPIE 4320 2001;764-774. [CrossRef]

12. Lepage M, Whittaker AK, Rintoul L, Back SA, Baldock C. Modelling of post-irradiation events in polymer gel dosimeters. Phys Med Biol 2001;46:2827-2839. [CrossRef]

13. Rintoul L, Lepage M, Baldock C. Radiation dose distribution in polymer gels by Raman spectroscopy. Appl Spectrosc 2003;57:51-57. [CrossRef] 
14. Taylor ML, Kron T, Franich RD. A contemporary review of stereotactic radiotherapy: Inherent dosimetric complexities and the potential for detriment. Acta Oncol 2011;50:483-508. [CrossRef]

15. Sigma Aldrich. Acrylamide properties in product catalogue; $2019 . \quad$ http://www.sigmaaldrich.com/catalog/product/sigma/ a9099?lang=en\&region=TR

16. Rogers DWO. Fifty years of Monte Carlo simulations for medical physics. Phys Med Biol 2006;51:R287-R301. [CrossRef]

17. Keall P, Kron T, Hoban P. A Monte Carlo technique to establish the water/tissue equivalence of phantom materials. Australas Phys Eng Sci Med 1993;16:125-128.

18. Hill R, Kuncic Z, Baldock $C$. The water equivalence of solid phantoms for low energy photon beams. Med Phys 2010;37:4355-4363. [CrossRef]

19. Rogers DWO, Walters B, Kawrakow I. BEAMnrc Users Manual. NRC Report PIRS-0509 (A) revL, NRC, Canada; 2015. https://nrc-cnrc. github.io/EGSnrc/doc/pirs509a-beamnrc.pdf

20. Forster RA, Cox JL, Barrett FR, et al. MCNP ${ }^{\text {TM }}$ Version 5. Nucl Instrum Methods Phy Res B NIMBEU 2004;213:82-86. [CrossRef]

21. Salvat F, Fernández-Varea JM, Sempau J. PENELOPE 2006 -a code system for Monte Carlo simulation of electron and photon transport; 2006. https://www.oecd-nea.org/science/pubs/2006/nea6222penelope.pdf

22. Agostinelli S, Allison J, Amako K, et al. Geant4 - a simulation toolkit. Nucl Instrum Methods A 2003;506:250-303. [CrossRef]

23. Arce $\mathrm{P}$, Banerjee $\mathrm{S}$, Boccali $\mathrm{T}$, et al. Simulation framework and $\mathrm{XML}$ detector description for the CMS experiment. Nucl Instrum Methods Phys Res A 2003;502:687-688. [CrossRef]
24. Arce P, Lagares JI, Harkness L, et al. GAMOS: A framework to do GEANT4 simulations in different physics fields with an user-friendly interface. Nucl Instrum Methods Phys Res A 2014;735:304-313. [CrossRef]

25. Senden RJ, De Jean P, McAuley KB, Schreiner LJ. Polymer gel dosimeters with reduced toxicity: a preliminary investigation of the NMR and optical dose-response using different monomers. Phys Med Biol 2006;51:3301-3314. [CrossRef]

26. Venning AJ, Hill B, Brindha S, Healy BJ, Baldock C. Investigation of the PAGAT polymer gel dosimeter using magnetic resonance imaging. Phys Med Biol 2005;50:3875-3888. [CrossRef]

27. Punnoose J, Xu J, Sisniega A, Zbijewski W, Siewerdsen JH. Technical note: Spektr 3.0-A computational tool for x-ray spectrum modeling and analysis. Med Phys 2016;43:4711-4717. [CrossRef]

28. Venning AJ, Nitschke KN, Keall PJ, Baldock C. Radiological properties of normoxic polymer gel dosimeters. Med Phys 2005;32:1047-1052. [CrossRef]

29. Hill R, Holloway L, Baldock C. A dosimetric evaluation of water equivalent phantoms for kilovoltage X-ray beams. Phys Med Biol 2005;50:N331-N344. https://doi.org/10.1088/0031-9155/50/21/ N06 [CrossRef]

30. Gorjiara T, Hill R, Kuncic Z, et al. Investigation of radiological properties and water equivalency of PRESAGE ${ }^{\circledR}$ dosimeters. Med Phys 2011;38:2265-2274. [CrossRef]

31. Gorjiara T, Hill R, Kuncic Z, Bosi S, Davies JB, Baldock C. Radiological characterization and water equivalency of genipin gel for $\mathrm{x}$-ray and electron beam dosimetry. Phys Med Biol 2011;56:4685-4699. [CrossRef] 